\title{
The incidence of post-ERCP pancreatitis is not reduced in patients given intravenous ketorolac for post-procedural abdominal pain
}

\author{
Alberto Mariani ${ }^{1, *}$, Marco Le Grazie ${ }^{1}$, Milena Di Leo ${ }^{1}$, Andrea Maini ${ }^{2}$ and Pier Alberto Testoni ${ }^{1}$ \\ 1 Gastroenterology and Gastrointestinal Endoscopy unit, Division of Experimental Oncology, IRCCS San Raffaele Scientific Institute, Vita-Salute San Raffaele \\ University, 20132 Milan, Italy \\ 2 Gastroenterology and Gastrointestinal Endoscopy unit, Division of General Surgery, 43036 Fidenza Hospital, Italy
}

\begin{abstract}
Introduction: Nonsteroidal anti-inflammatory drugs (NSAIDs) (e.g. indomethacin), administered rectally, seem to be effective in reducing post-ERCP pancreatitis (PEP). This effect seems lost with intramuscularly or intravenously administration. Our aim is to assess whether intravenous ketorolac given as an analgesic to patients with post-procedural abdominal pain reduces the rate of PEP. Material and methods: We retrospectively evaluated all hospital in-patients who had undergone therapeutic ERCP in a one-year period, comparing the rates of PEP in those who developed post-ERCP abdominal pain and those who did not. Patients with pain received ketorolac as analgesic NSAID (group A), patients without pain did not (group B). Patients with post-ERCP abdominal pain who were given ketorolac were also compared with those treated with non-NSAIDs because of contraindications. Results and discussion: A total of 587 patients underwent ERCP: 277 had post-procedural abdominal pain (47\%), 310 had none. Among patients with pain, the rates of PEP were $7.8 \%$ for those given ketorolac and $8.5 \%$ for those taking non-NSAIDs $(p=0.79)$. Comparing groups $A$ and $B$, the rates of PEP were not significantly different considering both all the patients (respectively $7.8 \%$ and $4.2 \%, p=0.08$ ) and those at high risk (3.8\% and $6 \%, p=0.6)$. In multivariate analysis, only age was significantly associated with PEP $(p=0.03)$; ketorolac was not $(p=0.16)$. Conclusions: Intravenous ketorolac to patients with post-ERCP abdominal pain seemed not to reduce the rate of PEP in either the whole group or in patients at high risk for this complication, compared to patients with no post-ERCP pain and no treatment.
\end{abstract}

Keywords: ERCP; pancreas; prevention; chemoprevention

\section{Introduction}

In clinical practice about $40 \%$ of patients undergoing ERCP complain of abdominal pain after the procedure [1]. This may be a consequence of bowel distension, but some studies have shown that it could also be an early predictor of post-ERCP pancreatitis (PEP) [2]. Regardless of the cause, however, patients with post-ERCP abdominal pain are usually given analgesic drugs. Nonsteroidal antiinflammatory drugs (NSAIDs) have a major first-line role.

Ketorolac is a NSAID with good analgesic action on postsurgical abdominal pain [3] on account of its effects on the endogenous opioid metabolism, mitochondrial calcium release and local nitric oxide production $[4,5]$. The antiinflammatory activity, on the other hand, is related to its ability to rapidly inhibit prostaglandin E2 synthesis through strong inhibition of both cyclooxygenase (COX) isoforms [6]. The inhibitory activity of NSAIDs on the inflammatory cascade is the reason why these drugs have been investigated for the prevention of post-ERCP pancreatitis. Several prospective randomized controlled trials and meta-analyses have shown both diclofenac and indomethacin to be effective for the prevention of PEP [7-12]. Based on these data recent European guidelines recommend the routine rectal administration of $100 \mathrm{mg}$ of diclofenac or indomethacin in all patients, if there are no contraindications, immediately before or after ERCP to reduce the risk of PEP [8]. However, surprisingly, a recent randomized controlled trial showed that rectal indomethacin was ineffective for PEP prevention [13]

*Corresponding author: Dr. Alberto Mariani, MD, Gastroenterology and Gastrointestinal Endoscopy Unit, Division of Experimental Oncology, VitaSalute San Raffaele University, IRCCS San Raffaele Scientific Institute, via Olgettina 60, 20132 Milan, Italy. Tel.: +39-2-26436301; Fax: +39-2-26433491; Email: mariani.alberto@hsr.it

Received 29 July 2016 Revised 8 September 2016 Accepted 17 September 2016 Published 28 September 2016

Citation: Mariani A, Grazie ML, Leo MD, Maini A, Testoni PA. The incidence of post-ERCP pancreatitis is not reduced in patients given intravenous ketorolac for post-procedural abdominal pain. J Hepatol Gastroenterol. 2016; 1(2):6-11. DOI: 10.14312/2399-8199.2016-2

Copyright: (c) 2016 Mariani A, et al. Published by NobleResearch Publishers. This is an open-access article distributed under the terms of the Creative Commons Attribution License, which permits unrestricted use, distribution and reproduction in any medium, provided the original author and source are credited. 
suggesting that NSAIDs alone may not be sufficient in chemoprevention of this complication. NSAIDs delivered orally (diclofenac) [14], intramuscularly (diclofenac) [15-16], or intravenously (i.v.: valdecoxib and ketorolac) [17-18] did not appear to help prevent PEP. It is still not clear whether this is because of differences in the pharmacokinetics depending on the route of administration. The greatest benefit for PEP prevention is expected in patients at high risk of this complication, for whom European guidelines recommend the placement of a prophylactic 5-french pancreatic stent in addition to the use of NSAIDs [8]. In these cases PEP is theoretically prevented by inhibition of the inflammatory cascade by NSAIDs combined with the facilitated pancreatic juice outflow into the duodenal lumen by the stents [19].

The aim of the present study was to assess whether intravenous ketorolac given early as an analgesic to patients with post-procedural abdominal pain lowered the rate of post-ERCP pancreatitis (PEP) in comparison with patients without post-procedural pain who were not given the drug.

\section{Materials and methods}

Data from all patients older than 18 years who had undergone therapeutic ERCP as in-patients in our tertiary referral center between January and December 2014 were analyzed. Data for each ERCP procedure were retrieved from a database system in which we collected each patient's main details, indication for the procedure, technical details of the procedure, final diagnoses, procedure-related complications [20], post-procedure clinical and enzymatic $24 \mathrm{~h}$ to $48 \mathrm{~h}$ course. We retrospectively compared the incidence of PEP in patients with and without onset of abdominal pain within about 60 min after the end of the procedure. The anesthetist gave patients with post-ERCP abdominal pain (group A) i.v. ketorolac tromethamine (1 vial of $30 \mathrm{mg}$ in $250 \mathrm{~mL}$ of saline solution; Mylan, Milan, Italy) as analgesic while they were in the recovery room; while patients without abdominal pain (group B) received no treatment. We have chosen the dose of $30 \mathrm{mg}$ of ketorolac, which is routinely administered by anesthetists, in our center, for the prevention of post- surgical pain in patients with normal renal function and in those aged over 65 years, for who the daily dose of ketorolac should not exceed $60 \mathrm{mg}$. Patients with post-ERCP pain with hypersensitivity to NSAIDs, recent peptic ulcer disease or active/recent gastrointestinal bleeding within the previous four weeks, renal dysfunction (creatinine $>1.4 \mathrm{mg} / \mathrm{dL}$ ) and use of NSAIDs during the week before ERCP (acetylsalicylic acid 325 mg daily or less was included) were given nonNSAID analgesics (paracetamol or tramadol).

In both groups, any one or more of the following risk factors [21] indicated the placement of a prophylactic pancreatic stent: suspected sphincter of Oddi dysfunction (SOD), previous acute pancreatitis, previous post-ERCP pancreatitis, papillarycannulation attemptsformorethan 10 minutes or more than 10 cannulation attempts, pancreatic duct contrast injection, pancreatic sphincterotomy, biliary sphincter dilation without biliary sphincterotomy. Patients without these risk factors were considered at low risk for PEP. Exclusion criteria were active pancreatitis and refusal or inability to give informed consent. The study design is shown in Figure 1. Informed consent for undergoing the procedures, intravenous ketorolac (when given) and data management for scientific purposes was routinely obtained from all patients. The study protocol was approved by the institutional ethics committee.

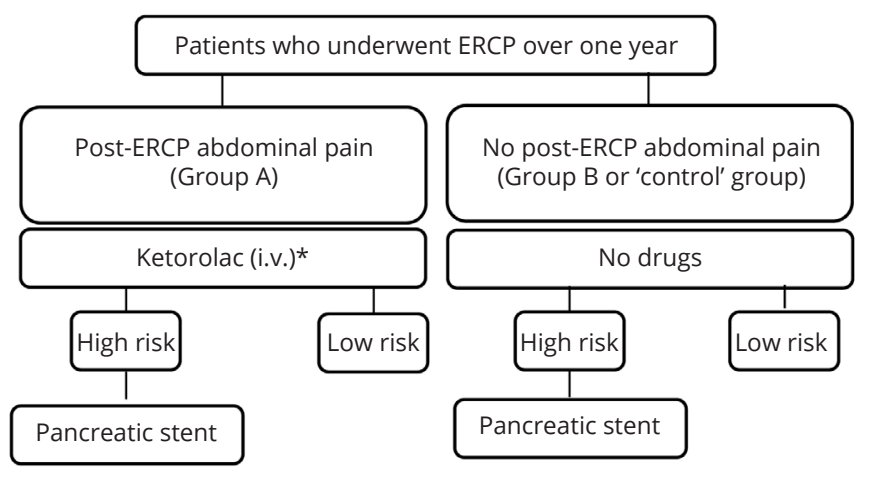

Figure 1 Study design.

Note: patients with NSAID intolerance were given non-NSAID analgesics.

\section{ERCP procedure}

All ERCP procedures were done by four endoscopists who had done more than 1000 ERCPs in their career, and had a current workload of at least 100 procedures per year. Trainees accomplished at least part of the procedure in about $25 \%$ of cases. ERCP procedures were done with a Pentax side-view endoscope (ED3480TK-ED3680TK) with the patient deeply sedated by i.v. infusion of propofol (Diprivan, Zeneca, Germany). Cannulation of the desired duct, either biliary or pancreatic, was attempted by advancing a hydrophilic guidewire, preloaded into a sphincterotome. The pancreatic stent was placed, searching the pancreatic duct with no more than five cannulation attempts or whenever the guidewire accidentally advanced into the main pancreatic duct.

\section{Post-ERCP abdominal pain}

Post-ERCP abdominal pain was defined as any kind of persistent pain in the upper abdominal quadrants occurring within about 60 min after the end of ERCP, not responsive to decompression using a transanal drainage tube. Post-ERCP pancreatitis was defined, according to consensus criteria [20], as post-procedural, new-onset or increased abdominal pain persisting for at least $24 \mathrm{~h}$, with serum amylase at least three times the upper limit of normal.

\section{Statistical analysis}

Continuous variables were expressed as group means \pm standard deviations, categorical variables as numbers and percentages. Categorical and continuous variables were analyzed with the chi-square test or Fisher's exact test and Student's t-test. Two-tailed P-values less than 0.05 were considered as indicating statistically significant results. Variables that were significant in the univariate analysis and/or on the basis of their clinical significance were included in the stepwise backward logistical regression 
analysis in order to identify significant independent factors related to PEP. Significance was set at $p<0.05$ with two side tails. Data were analyzed using the SPSS 21.0 system software (Chicago, IL, USA).

Statistical evaluation was done by Alberto Mariani, the first author of this paper.

\section{Results}

A total of 587 patients were included. Post-procedural abdominal pain was observed in 277 (47.2\%) and no pain in the remaining 310 (58.7\%). Of the 277 patients with pain $218(78.7 \%)$ received ketorolac, 59 non-NSAIDs (21.3\%). The rates of PEP were not significantly different in patients treated with ketorolac and those given non-NSAIDs (Table 1). In the whole population PEP was observed in 30 cases (5.7\%), 17 in group A and 13 in group $B(p=0.09)$ (Table 2). Patients with post-procedural pain who received ketorolac (group A) and those without pain (group B) were matched for sex and indication for ERCP, while age was significantly lower in group $A(p<0.0001)$. The most common indication for ERCP was bile duct stone disease followed by malignant biliary stenosis (Table 3).

Table 1 PEP numbers and rates in patients with post-procedural abdominal pain treated with ketorolac or non-NSAID analgesics.

\begin{tabular}{lcc}
\hline & Ketorolac (218) & Non-NSAIDs (59) \\
\hline PEP, no. (\%) & $17(7.8 \%)$ & $5(8.5 \%)^{*}$ \\
No PEP, no. (\%) & $201(92.2 \%)$ & $54(91.5 \%)$ \\
\hline
\end{tabular}

Note: ${ }^{*} \mathrm{p}=0.79$

Table 2 PEP numbers and rates in overall procedures, in group A (postprocedural abdominal pain treated with ketorolac) and group B (no pain, no drugs).

\begin{tabular}{lccc}
\hline & Group A (218) & Group B (310) & Total (528) \\
\hline PEP, no. (\%) & $17(7.8 \%)$ & $13(4.2 \%)^{*}$ & $30(5.7 \%)$ \\
No PEP, no. (\%) & $201(92.2 \%)$ & $297(95.8 \%)$ & $498(94.3 \%)$ \\
\hline
\end{tabular}

Note: ${ }^{*} \mathrm{p}=0.09$

Table 3 Patients' main characteristics and indications for ERCP in group A (post-procedural abdominal pain treated with ketorolac) and group B (no pain, no drugs).

\begin{tabular}{lccc}
\hline & $\begin{array}{c}\text { Group } A \\
(218)\end{array}$ & $\begin{array}{c}\text { Group B } \\
(310)\end{array}$ & $p$ \\
\hline Patients' main characteristics & & & \\
Female: 299 (56.6\%) & $117(53.7 \%)$ & $182(58.7 \%)$ & 0.09 \\
Mean age (SD) & $63.3(15.2)$ & $68.7(14.6)$ & $<0.0001$ \\
Indications for ERCP no. (\%) & & & \\
Bile duct stones: $280(53 \%)$ & $120(55 \%)$ & $160(51.6 \%)$ & 0.48 \\
Malignant stenosis: 161 (30.5\%) & $70(32.1 \%)$ & $91(29.4 \%)$ & 0.5 \\
Benign stenosis: $22(4.2 \%)$ & $8(3.7 \%)$ & $14(4.5 \%)$ & 0.66 \\
Biliary fistula: 9 (1.7\%) & $2(0.9 \%)$ & $6(1.9 \%)$ & 0.5 \\
Ampulloma: 10 (1.9\%) & $3(1.4 \%)$ & $6(1.9 \%)$ & 1.0 \\
Other indications: 46 (8, 7\%) & $15(6.8 \%)$ & $33(10.6 \%)$ & 0.2 \\
\hline
\end{tabular}

In all, 78 patients (14.8\%) presented clinical and/or technical risk factors and, as indicated by the protocol, underwent prophylactic pancreatic stenting: 39 were in group $A(17.9 \%)$ and 39 in group $B(12.6 \%)(p=0.1)$ (Table 4). In the whole population of patients with high risk factors and prophylactic pancreatic stenting the rates of PEP were lower but not significantly different from patients without risk factors and stenting. Table 5 shows the rates for patient- and procedure-related risk factors for PEP in the two groups.

Table 4 PEP rates in all patients and in the two groups based on risk factors (RF) for PEP. All patients with risk factors (RF +) had a prophylactic pancreatic stent.

\begin{tabular}{cccc}
\hline & Total cases & PEP & p \\
\hline Overall & 528 & $30(5.7 \%)$ & \\
RF + & $78^{*}$ & $3(3.8 \%)$ & 0.6 \\
RF - & 450 & $27(6.0 \%)$ & \\
Group A & 218 & $17(7.8 \%)$ & 0.7 \\
RF - + & 39 & $2(5.1 \%)$ & \\
Group B & 179 & $15(8.4 \%)$ & 1.0 \\
RF + & 310 & $13(4.2 \%)$ & \\
RF - & 39 & $1(2.6 \%)$ & \\
\hline
\end{tabular}

*In 15 of 78 cases (19.2\%) stenting failed and 2 of 15 cases developed PEP (13.3\%)

Table 5 Numbers and rates of patient- and procedure-related risk factors for PEP. Overall procedures, group A (post-procedural abdominal pain treated with ketorolac), and group B (no pain, no drugs).

\begin{tabular}{|c|c|c|c|c|}
\hline & $\begin{array}{l}\text { Total } \\
\text { (528) }\end{array}$ & $\begin{array}{l}\text { Group A } \\
\text { (218) }\end{array}$ & $\begin{array}{l}\text { Group B } \\
\text { (310) }\end{array}$ & $p$ \\
\hline $\begin{array}{l}\text { Patients with clinical and/ } \\
\text { or technical risk factors } \\
\text { no. }(\%)\end{array}$ & $78(14.8 \%)$ & $39(17.9 \%)$ & $39(12.6 \%)$ & 0.1 \\
\hline \multicolumn{5}{|l|}{ Patient-related risk factors } \\
\hline Suspected SOD no. (\%) & $22(10.1 \%)$ & $16(7.3 \%)$ & $6(1.9 \%)$ & 0.03 \\
\hline $\begin{array}{l}\text { Previous acute } \\
\text { pancreatitis no. (\%) }\end{array}$ & $21(4.0 \%)$ & $4(1.8 \%)$ & $17(5.5 \%)$ & 0.004 \\
\hline Previous PEP no. (\%) & $5(0.9 \%)$ & $2(0.9 \%)$ & $3(1 \%)$ & 1.00 \\
\hline \multicolumn{5}{|l|}{ Procedure-related risk factors } \\
\hline $\begin{array}{l}\text { Cannulation attempts } \\
>10 \text { min no. }(\%)\end{array}$ & $50(9.5 \%)$ & $36(16.5 \%)$ & 14 (4.5\%) & 0.0001 \\
\hline $\begin{array}{l}\text { Contrast injection in } \\
\text { MPD duct no. (\%) }\end{array}$ & $11(2.1 \%)$ & $7(3.2 \%)$ & $4(1.3 \%)$ & 0.21 \\
\hline $\begin{array}{l}\text { Pancreatic } \\
\text { sphincterotomy no. (\%) }\end{array}$ & $19(3.6 \%)$ & $10(4.6 \%)$ & $9(2.9 \%)$ & 0.35 \\
\hline $\begin{array}{l}\text { Biliary sphincter dilation } \\
\text { no. }(\%)\end{array}$ & $3(0.6 \%)$ & $1(0.5 \%)$ & $2(0.6 \%)$ & 1.00 \\
\hline
\end{tabular}

In the multivariate analysis, age was the sole factor related to PEP with a significant difference $(p=0.03)$. In this analysis ketorolac i.v. did not influence the rates of PEP ( $p$ $=0.16)$.

Among patients with post-procedural abdominal pain the rates for those with high risk factors were similar 
with ketorolac and non-NSAIDs: 11/59 (18.6\%) vs. 39/218 $(17.9 \%)(p=0.85)$. Of the five patients treated with nonNSAIDs who developed PEP, one had a pancreatic stent in place because of high risk factors, the other four did not $(p=1.0)$.

\section{Discussion}

In this study i.v. ketorolac did not reduce the rate of PEP in patients with post-ERCP abdominal pain to the level in those without pain. Similarly to what is reported elsewhere, $41.3 \%$ of patients complained of post-procedural abdominal pain. The patients treated with ketorolac could have been expected to have more PEP than the pain-free 'controls', as shown by Ho et al. [2]. However, non-NSAID analgesics too were associated with a higher rate of PEP. In fact, the rates of PEP in symptomatic patients treated with the analgesics were similar. We gave ketorolac with a primary analgesic purpose but we also wanted to retrospectively analyze its prophylactic properties on PEP since some NSAIDs, such as indomethacin and diclofenac, have proved effective in reducing this complication in an increasing number of studies [7-11]. This was particularly observed in patients at high-risk of PEP in which high "intrinsic pancreatic parenchyma hypersensitivity" or papillary edema and consequent temporary pancreatic ductal obstruction induced by repeated cannulation attempts are considered pathophysiological mechanisms of PEP. The activation of the inflammatory response induced by ERCP explains the use and efficacy of anti-inflammatory drugs for PEP prevention. A theoretical advantage of intravenous injection of NSAIDs, compared to the rectal route, could be the complete absorption of the drug; rectal absorption may be incomplete for anatomical reasons and rectal gas expulsion after the procedure because of air insufflation, which could even lead to expulsion of the suppository [22]; both these issues should be overcome by intravenous injection. However, despite recent doubts about usefulness of NSAIDs in preventing PEP [13], rectal but not intravenous NSAIDs seemed to be effective for this purpose, suggesting the importance of the route of administration to prevent this complication. As reported by Sotoudehmanesh et al. [23], the plasma half-life of indomethacin administered as a suppository is $4.5 \mathrm{~h}$ which should be adequate to influence the initial cellular activation of the pancreatic reaction after ERCP (within an appropriate therapeutic window; it should be adequate when PEP occurs). However, in this study population, i.v. ketorolac, although it has a similar half-life [24], did not prevent PEP. This might therefore be related to a difference in the pharmacokinetic profile. After i.v. injection the drug reaches a sudden high serum level, followed by a fast drop in concentration; after rectal administration, in comparison, the drug reaches lower concentrations but they persist longer probably on account of slower absorption.

Before this study, the effect of i.v. ketorolac on PEP had been assessed in only one study, reported in an abstract [18]. This was a retrospective case-control study on 245 patients who underwent high risk ERCP. The study did not find any real difference in ketorolac use between patients who developed PEP (25\%) and those who did not (24\%) ( $p$ =0.9).
Among NSAIDs administered intravenously, not only ketorolac but also valdecoxib, a selective COX-2 inhibitor, has been tested for preventing PEP. A randomized controlled trial (RCT) showed that i.v. valdecoxib did not reduce this complication [17]. Two RCTs showed that not only i.v. but also intramuscular NSAIDs, $75 \mathrm{mg}$ and $90 \mathrm{mg}$ diclofenac immediately after ERCP, did not reduce the rate of PEP $[15,16]$.

Other than the route of administration, a second possible reason why indomethacin and diclofenac are effective for preventing PEP and ketorolac is not is their different mechanism of action. Indomethacin and diclofenac are NSAIDs that inhibit the neutrophil-endothelial interaction and prostaglandin cascade, particularly at the level of COX enzymesand, upstream, atthelevel ofphospholipase-A2[2527]. Indomethacin was a potent inhibitor of phospholipaseA2 activity in serum from patients with acute pancreatitis, suggesting this enzyme is important in the pathophysiology of this condition [28]. We tested ketorolac, which does not inhibit phospholipase-A2, so this might explain its lack of effect in preventing PEP. On the other hand, ketorolac may interfere with the biological process that leads to pancreatitis, as it is a strong inhibitor of both COX isoforms [6], one of which (COX-2) is over-expressed in pancreatitis, suggesting its important pathophysiological role [29]. Two studies examined the effect of pharmacological inhibition of COX-2 in experimental acute pancreatitis and showed decreases in its severity and its systemic complications [30, 31]. As regards the pharmacological inhibition of COX-2 in the prophylaxis of PEP, a selective inhibitor (valdecoxib) has been studied, but the results were disappointing [17].

On the basis of our results, it is possible that the action of ketorolac was limited to the inhibition of COX and there was no inhibition of phospholipase-A2; this could explain its lack of effect for preventing PEP. Furthermore, another mechanism that could explain the negative effect of ketorolac on PEP prevention is that the drug inhibits COX-1 and, as a consequence, the synthesis of a protective factor against PEP, such as the case of prostaglandin [32].

Besides the considerations on the pharmacological characteristics of ketorolac and its route of administration, our study has other limitations. This was a single-center retrospective case-control study that compared two groups of patients with different clinical characteristics: age and post-ERCP pain, both theoretically unfavorable for patients treated with ketorolac. The treated patients were, overall, younger and this might have influenced its higher rate of $P E P$, since age was the only significant independent factor related to PEP in the multivariate test. The patients given ketorolac had a higher risk of developing PEP because this complication is marked by the onset of pain just at the end of ERCP, even if, as we noted before, a certain proportion of cases of post-procedural pain are related to bowel distension, particularly when air is used for insufflation during ERCP. We did not use carbon dioxide to reduce pain caused by bowel distension, a technique that has proved effective [1]. However, even with the limitation of different levels of basal abdominal pain in the two groups, 
it is important to underline that i.v. analgesics such as ketorolac are indicated in clinical practice for patients with post-ERCP pain.

Differently from i.v. ketorolac prophylaxis, this study shows that pancreatic stenting may reduce the rate of PEP in patients with risk factors even in those with postERCP pain. As suggested by ESGE guidelines [8], we placed a 5-french pancreatic stent only in patients with clinical and/or technical risk factors. The rate of PEP in patients with risk factors and pancreatic stenting was about $40 \%$ lower than in patients without risk factors and no stenting, independently of post-procedural pain, though the difference was not significant. Probably a larger series is needed to reach a significant difference. The rate of PEP was lowest $(2.6 \%)$ in patients with risk factors but without post-procedural pain.

Prophylactic pancreatic stent placement is cost-effective only in patients at high risk for PEP and if its success rate is over $75 \%$ [33]. In our study, pancreatic stenting gave $81.1 \%$ of success, and the rate of PEP in patients with risk factors and failed attempts at pancreatic stenting was lower $(13.3 \%)$ than reported elsewhere $[33,35]$. This might be due to our technical care to avoid more than five attempts to cannulate the main pancreatic duct. In any case we agree that caution is always needed when attempting prophylactic pancreatic stent placement because the incidence of PEP after failed attempts may be high.

In the present study, our strategy for reducing PEP followed ESGE guidelines, indicating NSAIDs for all patients undergoing ERCP and adding pancreatic stenting for those at high risk. In this last case, it is still debated whether prophylaxis with NSAIDs plus a stent is better than NSAIDs or the stent alone [36-38]. A recent trial suggests that prophylactic rectal indomethacin could replace prophylactic pancreatic stent in patients undergoing high risk ERCP, potentially improving clinical outcomes and reducing healthcare costs [34].

Moreover, a consideration should be made regarding the risk factors for PEP that we evaluated in our study. It's not clear why younger age was associated with a significantly higher rate of post-procedural abdominal pain and not PEP. In the literature [8], while younger age was often identified as a patient-related factor for PEP at univariate analyses, conflicting results were shown at multivariate analyses. This was the reason for the inclusion of younger age among the "likely risk factors" and not "definite risk factors" for PEP in the updated European guidelines of prophylaxis of PEP. However, our data confirm that both previous acute pancreatitis and repeated cannulation attempts certainly are risk factors for PEP.

\section{Conclusion}

Intravenous ketorolac at the end of ERCP, for analgesia in patients with post-procedural abdominal pain did not reduce the rate of PEP in comparison with patients without post-procedural pain, not needing an analgesic. In patients with clinical and/or technical high risk factors, pancreatic stenting reduced the rate of PEP independently from the presence or absence of post-ERCP pain. Controlled randomized trials are needed to further investigate the effect of ketorolac on the rate of PEP especially in high risk patients.

\section{Conflicts of interest}

Authors declare no conflicts of interest related to the manuscript.

\section{References}

[1] Maple JT, Keswani RN, Hovis RM, Saddedin EZ, Jonnalagadda S, et al. Carbon dioxide insufflation during ERCP for reduction of postprocedure pain: A randomized, double-blind, controlled trial. Gastrointest Endosc. 2009; 70(2):278-283.

[2] Ho K, Montes H, Sossenheimer MJ, Tham TC, Ruymann F, et al. Features that may predict hospital admission following outpatient therapeutic ERCP. Gastrointest Endosc. 1999; 49(5):587-592.

[3] Ready LB, Brown CR, Stahlgren LH, Egan KJ, Ross B, et al. Evaluation of intravenous ketorolac administered by bolus or infusion for treatment of post-operative pain. A double-blind, placebo controlled, multicenter study. Anesthesiology. 1994; 80(6):1277-1286.

[4] Buckley MM, Brodgen RN. Ketorolac. A review of its pharmacodynamic and pharmacokinetic properties, and therapeutic potential. Drugs. 1990; 39(1):86-109.

[5] Gillis JC, Brogden RN. Ketorolac. A reappraisal of its pharmacodynamic and pharmacokinetic properties and therapeutic use in pain management. Drugs. 1997; 53(1):139-188.

[6] Zhang Y, Shaffer A, Portanova J, Seibert K, Isakson PC. Inhibition of cyclooxygenase- 2 rapidly reverses inflammatory hyperalgesia and prostaglandin E2 production. J Pharmacol Exp Ther. 1997; 283(3):10691075.

[7] Elmunzer BJ, Scheiman JM, Lehman GA, Chak A, Mosler $P$, et al. A randomized trial of rectal indomethacin to prevent post-ERCP pancreatitis. N Eng J Med. 2012; 366(15):1414-1422.

[8] Dumonceau J, Andriulli A, Elmunzer BJ, Mariani A, Meister T, et al. Prophylaxis of post-ERCP pancreatitis: European Society of Gastrointestinal Endoscopy (ESGE) guideline. Endoscopy. 2014; 46(9):799-815.

[9] Sun HL, Han B, Zhai HP, Cheng XH, Ma K. Rectal NSAIDs for the prevention of post-ERCP pancreatitis: A meta-analysis of randomized controlled trials. Surgeon. 2014; 12(3):141-147.

[10] Leerhoy B, Nordholm-Carstensen A, Novovic S, Hansen MB, Jørgensen $\mathrm{LN}$. Diclofenac is associated with a reduced incidence of postendoscopic retrograde cholangiopancreatography pancreatitis. Pancreas. 2014; 43(8):1286-1290.

[11] Murray B, Carter R, Imrie C, Evans S, O'Suilleabhain C. Diclofenac reduces the incidence of acute pancreatitis after endoscopic retrograde cholangiopancreatography. Gastroenterology. 2003; 124(7):17861791.

[12] Thiruvengadam NR, Forde KA, Ma GK, Ahmad N, Chandrasekhara V, et al. Rectal indomethacin reduces pancreatitis in high and low-risk patients undergoing endoscopic retrograde cholangiopancreatography. Gastroenterology. 2016; 151(2):288-297.

[13] Levenick JM, Gordon SR, Fadden LL, Campbell Levy L, Rockacy MJ, et al. Rectal indomethacin does not prevent post-ERCP pancreatitis in consecutive patients. Gastroenterology. 2016; 150(4):911-917.

[14] Cheon YK, Cho KB, Watkins JL, McHenry L, Fogel EL, et al. Efficacy of diclofenac in the prevention of post-ERCP pancreatitis in predominantly high-risk patients: A randomized double-blind prospective trial. Gastrointest Endosc. 2007; 66(6):1126-1132.

[15] Senol A, Saritas U, Demirkan H. Efficacy of intramuscular diclofenac and fluid replacement in prevention of post-ERCP pancreatitis. World J Gastroenterol. 2009; 15(32):3999-4004.

[16] Park SW, Chung MJ, Oh TG, Park JY, Bang S, et al. Intramuscular diclofenac for the prevention of post-ERCP pancreatitis: a randomized trial. Endoscopy. 2015; 47(1):33-39.

[17] Bhatia V, Ahuja V, Acharya SK, Garg PK. A randomized controlled trial of valdecoxib and glyceryl trinitrate for the prevention of post-ERCP pancreatitis. J Clin Gastroenterol. 2011; 45(2):170-176.

[18] Lee PJ, Lopez R, Maurer WG, Tetzlaff J, Jang S, et al. Intravenous ketorolac does not prevent post-ERCP pancreatitis. Gastrointestinal Endoscopy. 2013; 77(5):391-392. 
[19] Sakai Y, Tsuyuguchi T, Yokosuka O. Clinical usefulness and current problems of pancreatic duct stenting for preventing post-ERCP pancreatitis. World J Clin Cases. 2014; 2(9): 426-431.

[20] Cotton PB, Lehman G, Vennes J, Geenen JE, Russell RC, et al. Endoscopic sphincterotomy complications and their management: An attempt at consensus. Gastrointest Endosc. 1991; 37(3):383-393.

[21] Testoni PA, Mariani A, Giussani A, Vailati C, Masci E, et al. Risk factors for post-ERCP pancreatitis in high and low-volume centers and among expert and non-expert operators: A prospective multicenter study. Am J Gastroenterol. 2010; 105(8):1753-1761.

[22] Shi H, Chen S, Swar G, Wang Y, Ying M. Carbon dioxide insufflation during endoscopic retrograde cholangiopancreatography: A review and meta-analysis. Pancreas. 2013; 42(7):1093-1100.

[23] Sotoudehmanesh R, Khatibian M, Kolahdoozan S, Ainechi S, Malboosbaf $\mathrm{R}$, et al. Indomethacin may reduce the incidence and severity of acute pancreatitis after ERCP. Am J Gastroenterol. 2007; 102(5):978-983.

[24] Jung D, Mroszczak E, Bynum L. Pharmacokinetics of ketorolac tromethamine in humans after intravenous, intramuscular and oral administration. Eur J Clin Pharmacol. 1988; 35(4):423-425.

[25] Cronstein BN, Van de Stouwe M, Druska L, Levin RI, Weissmann G. Nonsteroidal anti-inflammatory agents inhibit stimulated neutrophil adhesion to endothelium: adenosine dependent and independent mechanisms. Inflammation. 1994; 18(3):323-335.

[26] Vane JR, Botting RM. Mechanism of action of nonsteroidal antiinflammatory drugs. Am J Med. 1998; 104(3A):2S-8S.

[27] Singh N, Jabeen T, Somvanshi RK, Sharma S, Dey S, et al. Phospholipase A2 as a target protein for nonsteroidal anti-inflammatory drugs(NSAIDs): crystal structure of the complex formed between phospholipase A2 and oxyphenbutazone at 1.6 A resolution. Biochemistry. 2004; 43(46):14577-14583.

[28] Makela A, Kuusi T, Schroder T. Inhibition of serum phospholipase-A2 in acute pancreatitis by pharmacological agents in vitro. Scand J Clin Lab Invest. 1997; 57(5):401-407.

[29] Zabel-Langhennig A, Holler B, Engeland K, Mössner J. Cyclooxygenase-2 transcription is stimulated and amylase secretion is inhibited in pancreatic acinar cells after induction of acute pancreatitis. Biochem Biophys Res Commun. 1999; 265(2):545-549.

[30] Ethridge RT, Chung DH, Slogoff $M$, Ehlers RA, Hellmich MR, et al. Cyclooxygenase-2 gene disruption attenuates the severity of acute pancreatitis and pancreatitis-associated lung injury. Gastroenterology. 2002; 123(4):1311-1322.

[31] Seo SW, Jung WS, Piao TG, Hong SH, Yun KJ, et al. Selective cyclooxygenase-2 inhibitor ameliorates cholecystokinin-octapeptideinduced acute pancreatitis in rats. World J Gastroenterol. 2007; 13(16):2298-2304.

[32] Jaworek J, Bonior J, Tomaszewska R, Jachimczak B, Kot M, et al. Involvement of cyclooxygenase-derived prostaglandin E2 and nitric oxide in the protection of rat pancreas afforded by low dose of lipopolysaccharide. J Physiol Pharmacol. 2001; 52(1):107-126.

[33] Das A, Singh P, Sivak MV, Chak A. Pancreatic-stent placement for prevention of post-ERCP pancreatitis: A cost-effectiveness analysis. Gastrointest Endosc. 2007; 65(7):960-968.

[34] Freeman ML, Overby C, Qi D. Pancreatic stent insertion: Consequences of failure and results of a modified technique to maximize success. Gastrointest Endosc. 2004; 59(1):8-14.

[35] Choksi NS, Fogel EL, Cote GA, Romagnuolo J, Elta GH, et al. The risk of post-ERCP pancreatitis and the protective effect of rectal indomethacin in cases of attempted but unsuccessful prophylactic pancreatic stent placement. Gastrointest Endosc. 2015; 81(1):150-155.

[36] Elmunzer BJ, Higgins PD, Saini SD, Scheiman JM, Parker RA, et al. Does rectal indomethacin eliminate the need for prophylactic pancreatic stent placement in patients undergoing high-risk ERCP? Post hoc efficacy and cost-benefit analyses using prospective clinical trial data. Am J Gastroenterol. 2013; 108(3):410-415.

[37] Arain MA, Freeman ML. Pharmacologic prophylaxis alone is not adequate to prevent post-ERCP pancreatitis. Am J Gastroenterol. 2014; 109(6): 910-912.

[38] Elmunzer BJ, Waljee AK. Can rectal NSAIDs replace prophylactic pancreatic stent placement for the prevention of post-ERCP pancreatitis? Gastroenterology. 2014; 146(1):313-315. 